\title{
Polímeros Bioreabsorvíveis na Engenharia de Tecidos
}

\author{
Samuel H. Barbanti, Cecília A. C. Zavaglia \\ Faculdade de Engenharia Mecânica, UNICAMP \\ Eliana A. R. Duek \\ Centro de Ciências Médicas e Biológicas, PUC-SP
}

\begin{abstract}
Resumo: A Engenharia de Tecidos consiste em um conjunto de conhecimentos e técnicas para a reconstrução de novos órgãos e tecidos. Baseada em conhecimentos das áreas de ciência e engenharia de materiais, biológica e médica, a técnica envolve a expansão in vitro de células viáveis do paciente doador sobre suportes de polímeros bioreabsorvíveis. O suporte degrada enquanto um novo órgão ou tecido é formado. Os poli( $\alpha$-hidróxi ácidos) representam a principal classe de polímeros sintéticos bioreabsorvíveis e biodegradáveis utilizados na engenharia de tecidos. No desenvolvimento e na seleção desses materiais, o tempo de degradação é fundamental para o sucesso do implante. Os estudos e os desafios atuais são normalmente direcionados ao entendimento das relações entre composição química, cristalinidade, morfologia do suporte, e o processamento desses materiais. Este artigo faz uma revisão dos trabalhos recentes sobre a utilização dos polímeros sintéticos bioreabsorvíveis como suportes na engenharia de tecidos.
\end{abstract}

Palavras-chave: Engenharia de tecidos, polímeros bioreabsorvíveis, poli( $\alpha$-hidróxi ácidos).

\section{Bioresorbable Polymers in Tissue Engineering}

Abstract: Tissue Engineering is based on a group of techniques for the reconstruction of new organs and tissues. Based on knowledge of materials science and engineering, biology and medicine, the technique involves the in vitro expansion of viable cells obtained from the patient on the polymeric scaffolds. The scaffold degrades while a new organ or tissue is formed. The poly( $\alpha$-hydroxy acids) are the principal biodegradable and bioresorbable polymers used in tissue engineering. In developing and selecting bioresorbable scaffolds, the degradation time is fundamental for successful biocompatibility and biofuncionality. Hence, degradation studies often address variables such as the chemical composition, crystallinity, morphology of the scaffold and the processing of these materials. This paper reviews recent work in bioresorbable polymers used as scaffolds in the tissue engineering.

Keywords: Tissue engineering, bioresorbable polymers, poly( $\alpha$-hydroxy acids).

\section{Introdução}

Quando a estrutura biológica de um órgão ou tecido não pode ser reparada, a alternativa viável para o restabelecimento das funções normais do paciente é repô-la com um implante feito de um biomaterial ${ }^{[1]}$. Em função do tempo de permanência no corpo humano, os implantes podem ser classificados em dois grandes grupos, permanentes ou temporários.

Implantes permanentes quase sempre geram fenômenos crônicos de inflamação, sendo uma resposta tipicamente benigna a um corpo estranho, mas que podem conduzir a complicações clínicas mais severas, como a contração dos tecidos. Dentre os materiais utilizados como implantes, os polímeros apresentam grande potencial de uso, pois são, geralmente, fáceis de produzir, manusear e apresentam características mecânicas semelhantes aos dos materiais biológicos ${ }^{[2]}$.

Desde a década de 1960, implantes temporários, confeccionados de polímeros bioreabsorvíveis, ganharam uma importância crescente na área médica, sendo utilizados em um amplo número de aplicações no corpo humano, tais como: suturas cirúrgicas ${ }^{[3]}$, sistemas para liberação controlada de drogas $^{[4]}$, stents ${ }^{[5]}$ e dispositivos ortopédicos ${ }^{[6]}$. Atualmente fazem parte do cotidiano dos centros cirúrgicos no mundo inteiro.

Embora muitos dispositivos protéticos artificiais estejam disponíveis, poucos podem substituir completamente todas as complexas funções biológicas. Em situações clínicas mais severas somente o transplante do órgão retoma as atividades orgânicas. Assim, de uma forma idealizada, a melhor alternativa seria obter um novo órgão ou tecido, substituindo aquele que não desempenha normalmente suas funções. Nos dias de hoje, a idéia da reconstrução de órgãos e tecidos criados em laboratório é amplamente difundida e investigada no mundo todo ${ }^{[7,8]}$.

\section{Engenharia de tecidos}

A técnica, conhecida como Engenharia de Tecidos, consiste na regeneração de órgãos e tecidos vivos, através

Autor para correspondência: Samuel H. Barbanti, Departamento de Engenharia de Materiais, Faculdade de Engenharia Mecânica, UNICAMP, Caixa Postal 6122, CEP: 13083-970, Campinas, SP. E-mail: samuel@fem.unicamp.br 
Engenharia de Tecidos

Tecido Doador

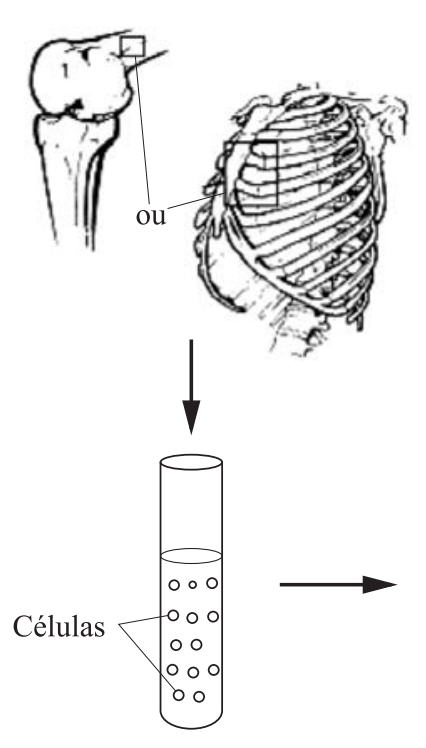

Suporte Polimérico

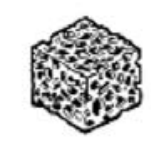

ou

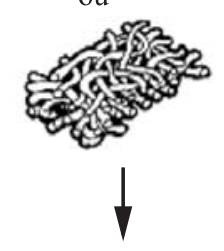

Cultura de Células in vitro
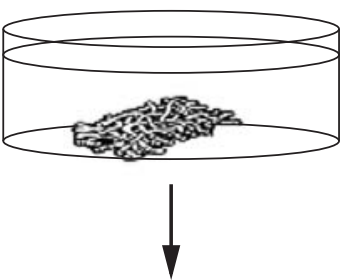

Implante

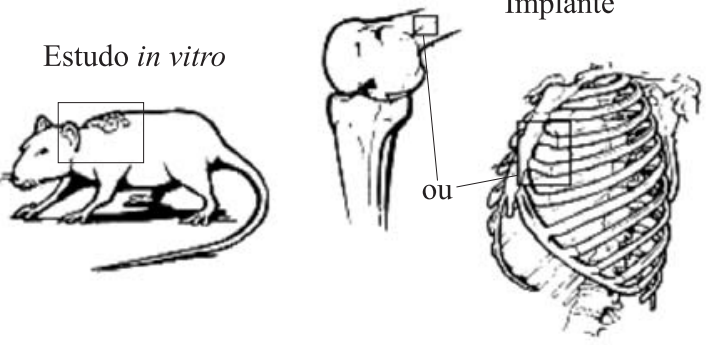

Figura 1. Técnica da engenharia de tecido.

do recrutamento de tecido do próprio paciente, que são dissociados em células e cultivadas sobre suportes biológicos ou sintéticos, conhecidos como scaffolds (suportes, matrizes tridimensionais, arcabouços, estruturas, etc), para então serem reinseridos no paciente. Como uma ciência multidisciplinar, os trabalhos envolvem conhecimentos das áreas de biologia, ciências da saúde e de engenharia e ciência dos materiais ${ }^{[9,10]}$.

A Figura 1, adaptada de Freed et al. ${ }^{[11]}$, ilustra o desenvolvimento idealizado da técnica da engenharia de tecidos.

Buscando uma padronização tanto na terminologia como na metodologia de pesquisa e aplicação dos produtos preparados pela engenharia de tecidos, a regulamentação vem sendo feita por normas ASTM (entre elas F2312-03, F2027-00e1 e F215002e1) e por órgãos governamentais de países da Europa, Japão, Canadá e outros ${ }^{[12]}$. De uma forma geral, a preparação dos produtos da engenharia de tecidos seguem as seguintes etapas:

(I) Seleção e processamento do suporte

(II) Inoculação da população celular sobre o suporte

(III) Crescimento do tecido prematuro

(IV) Crescimento do tecido maturado em sistema fisiológico (bioreator)

(V) Re-Implante cirúrgico

(VI) Assimilação do produto.
Estratégia I

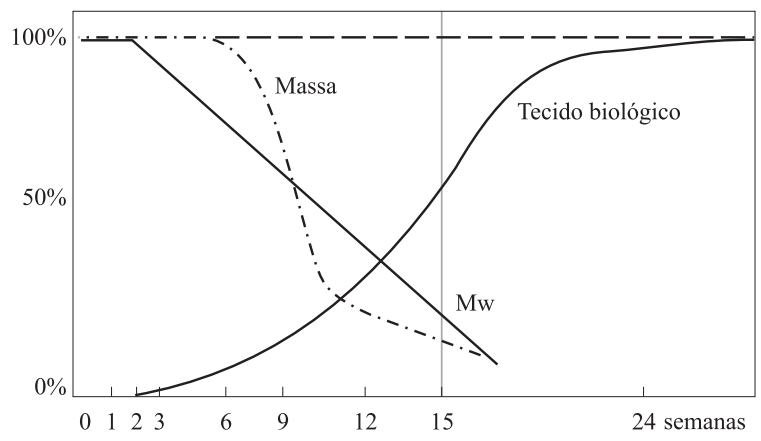

Figura 2. Estratégia I de seleção de polímeros bioreabsorvíveis aplicados à engenharia de tecidos (a linha vertical cinza indica o momento de implante in vivo).

\section{Suportes (Scaffolds)}

Considerado de forma integrada, tanto sob o aspecto da engenharia de materiais e do tipo de tecido e reparo necessário, o primeiro passo para a reconstrução de um órgão ou tecido visa à seleção do suporte para as células. A seleção leva em consideração tanto o tipo, local da lesão, como a sua extensão, podendo seguir basicamente duas estratégias de aplicação, quando preparado com polímeros bioreabsorvíveis ${ }^{[13]}$.

Na primeira estratégia (Figura 2), o material polimérico é desenvolvido de forma a suportar física e mecanicamente as células, da inoculação até o reimplante no organismo hospedeiro. O implante do conjunto polímero e células ocorrem com um tecido prematuro formado e o polímero é remodelado pela degradação in vivo, numa razão proporcional ao crescimento celular e à solicitação mecânica. Sua função é proporcionar suporte para o crescimento celular e adicionalmente servir como substituto mecânico/estrutural do tecido original até a formação do novo tecido e sua bioreabsorção completa.

Na segunda estratégia (Figura 3), o implante ocorre com tecido maduro formado. O suporte polimérico é dimensionado com propriedades mecânicas e tempo de degradação adequados para a inoculação das células até a sua inserção num bioreator, onde ocorrerá a formação do tecido maduro. Nesta etapa, as células semeadas proliferam e secretam ma-

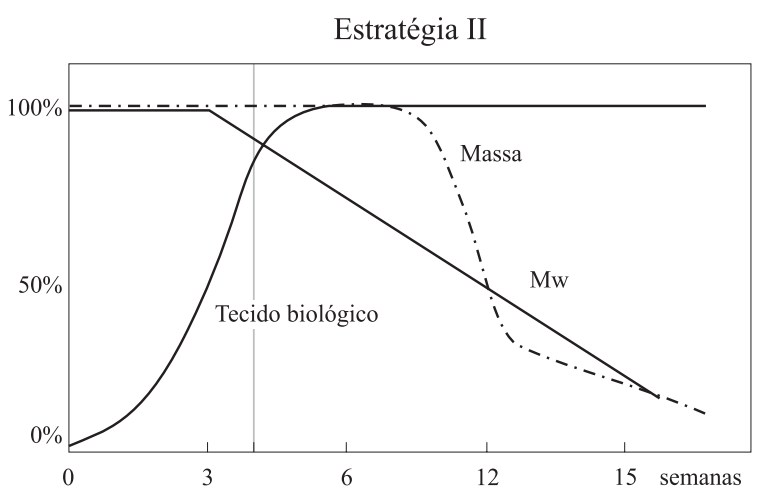

Figura 3. Estratégia II de seleção de polímeros bioreabsorvíveis aplicados à engenharia de tecidos (a linha vertical cinza indica o momento de implante in vivo) 
triz extracelular durante a cultura in vitro, enquanto o polímero é degradado e reabsorvido gradualmente, permitindo espaço para a proliferação celular e formação do tecido no reator biológico. Somente após a formação do tecido, o implante é inserido no organismo.

\section{Polímeros Bioreabsorvíveis, os poli( $\alpha$-hidróxi ácidos)}

Baseado nas estratégias anteriores, a primeira etapa na engenharia de tecidos inicia-se com o desenvolvimento, seleção e o processamento dos suportes. O uso de polímeros bioreabsorvíveis como suporte para a cultura de células vem tendo destaque na engenharia de tecidos ${ }^{[14]}$.

Os termos utilizados para os conceitos de biodegradação, bioabsorção e bioreabsorção são distintos e freqüentemente usados na engenharia de tecidos. Devido à falta de padronização para os termos utilizamos neste trabalho a definição fornecida por Michel Vert, químico e diretor do Centro de Pesquisas em Biopolímeros Artificiais, da Universidade de Montpellier 1, França, um dos pioneiros e líderes mundiais no estudo de materiais poliméricos bioreabsorvíveis.

Segundo Vert et al.$^{[15]}$ biodegradável é um termo utilizado para polímeros e dispositivos sólidos que devido à degradação macromolecular sofrem dispersão in vivo, mas sem a eliminação dos produtos e subprodutos pelo organismo. Polímeros biodegradáveis podem ser atacados por elementos biológicos de forma que a integridade do sistema seja afetada, formando-se fragmentos ou outros subprodutos de degradação, que podem ser removidos do seu local de ação, mas não necessariamente do organismo.

Bioreabsorviveis são materiais poliméricos e dispositivos sólidos que mostram degradação através da diminuição de tamanho e que são reabsorvidos in vivo; i.e. materiais que são eliminados por rotas metabólicas do organismo. Bioreabsorção é um conceito que reflete a eliminação total do material e dos subprodutos de degradação (compostos de baixa massa molar) sem efeitos colaterais residuais. $\mathrm{O}$ uso da palavra "bioreabsorção" é utilizado quando a eliminação é total.

Bioabsorvível são materiais poliméricos e dispositivos que podem se dissolver em fluidos corpóreos sem qualquer clivagem da cadeia macromolecular ou diminuição de massa molecular. Por exemplo, este é o caso da lenta dissolução de implantes solúveis em fluidos orgânicos. Um polímero bioabsorvível pode ser bioreabsorvível se suas macromoléculas são excretadas.

Dentre os polímeros sintéticos biodegradáveis e bioreabsorvíveis encontram-se os poli( $\alpha$-hidróxi ácidos), representantes de uma classe de poliésteres alifáticos sintéticos, os quais fazem parte o poli(ácido glicólico) (PGA), poli(ácido láctico) (PLA), poli(ácido láctico-co-ácido glicólico) (PLGA), poli( $\varepsilon$-caprolactona) (PCL), seus copolímeros e outros. Originalmente usados como fios de sutu$\mathrm{ra}\left(\right.$ Dexon $^{\circledR}$, Vicryl $^{\circledR}$, Maxon $^{\circledR}$, PDS $^{\circledR}$, etc $)$, atualmente os poli $(\alpha$ hidróxi ácidos) podem ser encontrados em diversos produtos

Tabela 1. Poli( $\alpha$-hidróxi ácidos), polímeros sintéticos bioreabsorvíveis.

\begin{tabular}{|c|c|c|c|c|c|c|}
\hline Polímero & Sigla & Fórmula & $\operatorname{Tg}\left({ }^{\circ} \mathrm{C}\right)$ & $\operatorname{Tm}\left({ }^{\circ} \mathbf{C}\right)$ & $\begin{array}{c}\text { Módulo de } \\
\text { Elasticidade } \\
\text { (GPa) }\end{array}$ & $\begin{array}{c}\text { Tempo de } \\
\text { Degradação } \\
\text { (meses) }^{\text {b }}\end{array}$ \\
\hline Poli(ácido glicólico) & PGA & & $35-40$ & $225-230$ & 8,4 & $6-12$ \\
\hline Poli(L-ácido láctico) & PLLA & & $60-65$ & $173-178$ & 2,7 & $>24$ \\
\hline Poli(D,L-ácido láctico) & PDLLA & & $55-60$ & Amorfo & 1,9 & $12-16$ \\
\hline $\begin{array}{l}\text { Poli(D,L-ácido láctico } \\
\text {-co-ácido glicólico) }\end{array}$ & PLGA & & $45-50^{\mathrm{a}}$ & Amorfo & 2,0 & $1-2$ \\
\hline Poli(e-caprolactona) & PCL & & $(-65)(-60)$ & $58-63$ & 0,4 & $24-36$ \\
\hline
\end{tabular}


comerciais de fixação óssea, também aprovados pelo Food and Drug Administration (FDA), (Biofix ${ }^{\circledR}$, Fix Sorb ${ }^{\circledR}$, Neofix $^{\circledR}$, ResorPin ${ }^{\circledR}$, etc). A Tabela 1 fornece algumas propriedades destes polímeros ${ }^{[16,17]}$.

$O$ processo de biodegradação e bioreabsorção dos poli $(\alpha-$ hidróxi ácidos) é descrito na literatura como sendo uma sucessão de eventos. Exposto aos fluidos aquosos do corpo, inicialmente o material sofre hidratação. Com a presença das moléculas de água, o processo de degradação dá-se através da hidrólise das ligações ésteres, originando produtos na forma de oligômeros (ou monômeros) solúveis e não tóxicos. A degradação prossegue por um processo biologicamente ativo (por enzimas) ou pela clivagem hidrolítica passiva, sendo caracterizada pela perda de massa, diminuição de massa molar ponderal média $(\overline{\mathrm{M}} \mathrm{w})$ e pela perda das suas propriedades mecânicas, como a resistência à tração e à compressão ${ }^{[17,18]}$.

O mecanismo da degradação in vitro dos polímeros bioreabsorvíveis tem sido avaliado nos últimos anos e demonstra ser um processo heterogêneo na extensão do material. Dentre os produtos da hidrólise das ligações ésteres, a presença de terminais ácidos catalisa a reação de degradação. É o chamado efeito autocatalítico dos poli( $\alpha$-hidróxi ácidos). O processo é homogêneo inicialmente, gerando oligômeros solúveis em água em toda a extensão do material. Os produtos presentes na superfície da matriz são difundidos para o meio, entretanto, a baixa taxa de difusão dos produtos da reação no interior do material gera um acúmulo de ácidos,

(a)

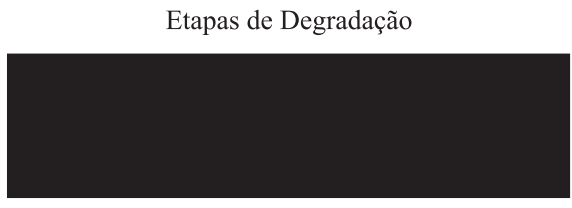

(b)

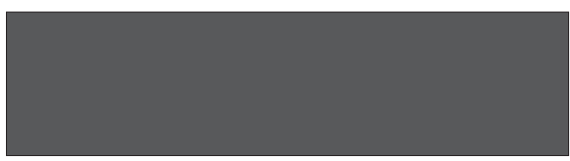

(c)

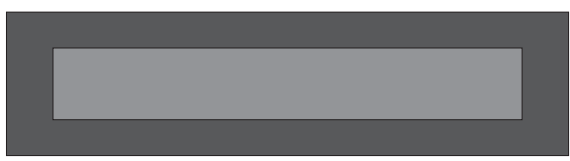

(d)

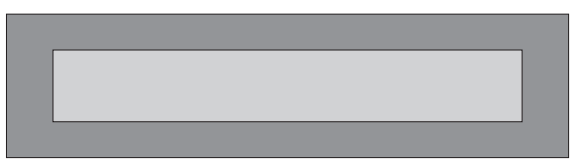

(e)

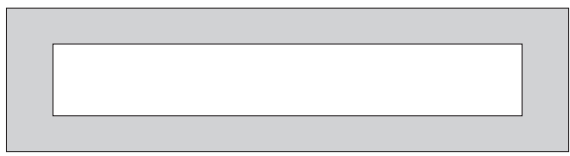

Figura 4. Degradação dos poli( $\alpha$-hidróxi ácidos) (PLA, PGA, PCL, etc) pelo efeito autocatalítico ${ }^{[22]}$. (a) Amostra inicial, não degradada, (b) Absorção de água e início da hidrólise com diminuição da massa molecular, (c) Diferenciação da degradação entre a superfície e o centro da amostra, com acentuada diminuição da massa molar do centro, (d) Difusão de oligômeros solúveis através da camada superficial da amostra, (e) Estágio final da degradação com a presença de uma carcaça da amostra. fazendo com que estruturas densas tenham uma erosão inicial na superfície, mas apresentando uma degradação mais acentuada no centro ${ }^{[19]}$.

A autocatálise foi avaliada inicialmente por Li et al. ${ }^{[20]}$ estudando copolímeros de PDLLA. Segundo os autores, após 12 semanas de degradação in vitro em tampão fosfato, o interior do material sofre significativa diminuição de massa. Resultados semelhantes são obtidos nos estudos in vivo. A degradação de maneira heterogênea foi avaliada e confirmada pelos estudos subseqüentes ${ }^{[21,22]}$.

A bioreabsorção pelo organismo ocorre quando a biodegradação gera produtos e subprodutos com as características dos metabólitos orgânicos, especificamente os ácidos do Ciclo de Krebs. Terminada a hidrólise do material a degradação segue o processo de oxidação a ácido láctico (para o PLA) e conversão das unidades de PGA em glicina, que por sua vez são convertidos em ácido pirúvico. Na presença da acetil coenzima $\mathrm{A}$, ocorre a liberação de $\mathrm{CO}_{2} \mathrm{e}$, conseqüentemente, a decomposição em citrato. $\mathrm{O}$ citrato será então incorporado no Ciclo de Krebs, resultando em $\mathrm{CO}_{2} \mathrm{e}$ $\mathrm{H}_{2} \mathrm{O}$, podendo sua eliminação ser feita através da urina e da respiração. O material foi reabsorvido e metabolizado ${ }^{[23]}$.

Em estudos in vivo, o processo de biodegradação e bioreabsorção é um mecanismo complexo de eventos celulares e bioquímicos. Com o implante do material sintético o organismo promove uma típica resposta à uma reação inflamatória de corpo estranho. A influência na degradação pela presença de peróxidos, enzimas e células fagocitárias, representa ainda hoje um importante enfoque nas pesquisas dos polímeros bioreabsorvíveis ${ }^{[24,25]}$.

A degradação in vitro mostra-se como uma boa alternativa quando comparados aos estudos in vivo, sendo fundamentais e necessários. Os custos são menores, o processo pode ser acelerado e as condições do ensaio, como temperatura,

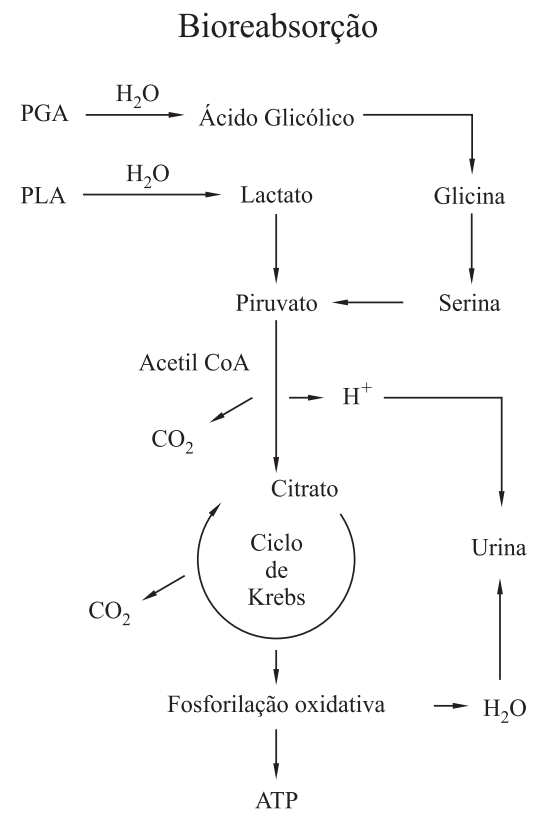

Figura 5. Rota metabólica de bioreabsorção dos poli( $\alpha$-hidróxi ácidos) (PLA e PGA). 
$\mathrm{pH}$, produtos e subprodutos de degradação, podem ser quantificados e monitorados ${ }^{[26-28]}$.

\section{Fatores que Influenciam a Degradação}

Muitos fatores determinam a resposta inflamatória e a taxa de degradação dos polímeros bioreabsorvíveis, entre eles: local de implante, solicitação mecânica, massa molar, distribuição da massa molar, composição química/esterioisométrica, cristalinidade, sua morfologia, envolvendo o tamanho e geometria do suporte desenvolvido, porosidade, rugosidade da superfície, energia livre de superfície, carga da superfície, $\mathrm{pH}$, presença de aditivos e outros ${ }^{[16]}$. Dentre esses fatores podemos destacar:

\section{Localização do Implante}

$\mathrm{Na}$ localização do implante deve-se levar em conta a vascularização local e a solicitação mecânica. Se um polímero bioreabsorvível é implantado num local de alta vascularização (grande atividade vital), sua velocidade de degradação será mais rápida em relação à uma região menos vascularizada, de funções passivas. Locais de grande solicitação mecânica também têm sido descritos como aceleradores da degradação ${ }^{[29]}$.

\section{Composição Química}

No caso do poli(ácido láctico), a quiralidade do carbono $\alpha$ permite a síntese de compostos enantiômeros, levo (L) e destro (D) rotatórios, dando origem à uma família de polímeros: poli(L-ácido láctico) (PLLA), poli(D, L-ácido láctico) (PDLLA) e copolímeros em diferentes proporções. Segundo Bendix ${ }^{[30]}$, devido à distribuição aleatória das unidades L e D na cadeia polimérica, o polímero racêmico não possui domínios cristalinos, sendo um material amorfo e com propriedades mecânicas significativamente menores quando comparado ao semicristalino PLLA. A cinética de hidrólise do PDLLA tem sido verificada e demonstra ser mais rápida do que o PLLA (valores na Tabela 1).

O grupo metila presente nas cadeias de PLA é responsável pelo impedimento estérico na reação de hidrólise. Dessa forma, a presença de unidades de ácido glicólico favorece a penetração da água e conseqüentemente a taxa de degradação.

Publicada em 1977, a Figura 6 mostra a meia-vida (perda de massa em 50\%) em função da razão de unidades de ácido láctico e ácido glicólico em copolímeros PLGA implantados

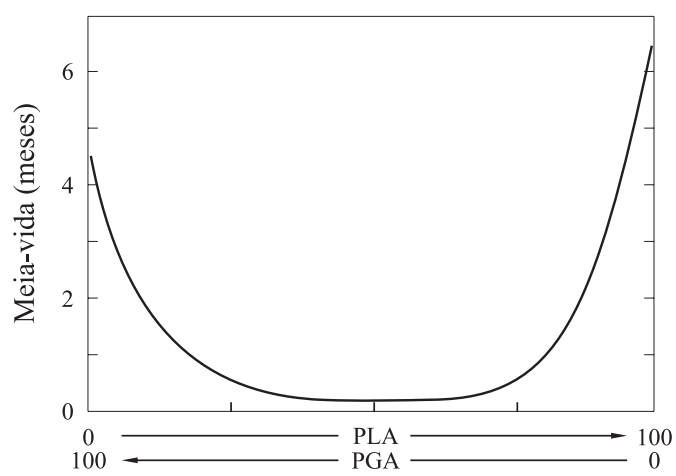

Figura 6. Perda de massa (em meses). em ratos. Para copolímeros PLGA, a composição química das unidades de ácido láctico e ácido glicólico é avaliada como fator determinante na degradação por hidrólise. Neste estudo, Miller et al. ${ }^{[31]}$ avaliaram a degradação in vivo, durante 11 meses, para amostras de PLA(100), PLGA(25/75), PLGA(50/50), PLGA(75/25) e PGA(100), através da inclusão de isótopos ${ }^{14} \mathrm{C} \mathrm{e}{ }^{3} \mathrm{H}$ na cadeia polimérica. Medindo-se a perda de radioatividade dos implantes em ratos, os autores concluem que a meia-vida é menor para as estruturas de PLGA (50/50) e está fundamentalmente relacionada com a cristalinidade dos materiais.

\section{Cristalinidade}

A influência da cristalinidade na velocidade de degradação dos polímeros bioreabsorvíveis foi relatada por Fischer et al. ${ }^{[32]}$ através de distribuições trimodais de $\overline{\mathrm{M}} \mathrm{w}$ utilizando dados de degradação in vitro para copolímeros de PDLLA. A degradação de polímeros parcialmente cristalinos ocorre, fundamentalmente, em duas etapas:

Devido à disposição espacial das cadeias poliméricas, o efeito da cristalinidade influi na taxa de absorção de água pelo polímero. O primeiro estágio de degradação consiste na penetração e difusão das moléculas de água nas regiões amorfas do material, e subseqüente cisão hidrolítica das ligações ésteres das cadeias poliméricas. O segundo estágio se dá quando parte considerável da região amorfa esta degradada, e prossegue no centro dos domínios cristalinos ${ }^{[19]}$. Dessa forma, para polímeros parcialmente cristalinos, a literatura descreve um aumento porcentual da porção cristalina devido à absorção dos fragmentos pela rede cristalina e pela formação de novos cristais, através do rearranjo das cadeias de menor massa molar originadas no processo de degradação ${ }^{[33]}$.

\section{Morfologia}

A influência da porosidade e geometria do suporte polimérico é também relatada como um dos fatores determinantes na velocidade de degradação e indução ao crescimento celular ${ }^{[34]}$.

Os principais estudos da influência da morfologia na degradação dos suportes bioreabsorvíveis têm sido realizados pelo grupo de pesquisa liderado por Antonio G. Mikos, da Universidade de Rice, EUA. Com diversos trabalhos e patentes relacionadas à metodologia de preparo de suportes bioreabsorvíveis e suas aplicações, Mikos propõe, no início da década de 90 , que a taxa de penetração e crescimento celular em suportes porosos está diretamente relacionada com o tamanho e distribuição do tamanho dos poros no material[ ${ }^{[35]}$.

Os autores, num extenso estudo, prepararam réplicas porosas de PLLA (amorfo e cristalino) e PLGA 50/50 através da técnica de evaporação de solvente com adição de cloreto de sódio, com partículas de sal variando entre $250-500 \mu \mathrm{m}$, obtendo estruturas que possuíam em média $85 \%$ de porosidade com tamanhos de poros variando entre 50-150 $\mu \mathrm{m}$. Através de implantes subcutâneos, a invasão celular foi avaliada em 25 dias de experimento. Os autores concluem que a invasão e o crescimento celular estão diretamente relaciona- 
dos com o tamanho dos poros e a cristalinidade do material. Na faixa de 50-150 $\mu$ m, para ambos os polímeros, quanto maior o tamanho do poro do material maior foi a taxa de crescimento celular, devido à facilidade de difusão dos nutrientes dos fluidos orgânicos locais.

Lu et al. ${ }^{[36]}$ descrevem o estudo da degradação in vitro, em tampão fosfato $(\mathrm{pH}=7,4)$, de estruturas porosas de PLLA preparadas pela adição de sal em diferentes granulometrias e concentrações. Os autores concluem que a influência do tamanho do poro (e distribuição do tamanho de poros) não tem influência na morfologia porosa durante 46 semanas de degradação, entretanto, o efeito autocatalítico é observado e descrito como sendo uma função da espessura da parede do poro. Quanto maior a espessura, menor a difusão dos produtos ácidos de degradação e conseqüentemente maior a velocidade de perda de massa.

Estudos da degradação de membranas densas e porosas de PLLA em tampão fosfato $(\mathrm{pH}=7,4)^{[37]}$ e em meio de cultura HAM F $10^{[38]}$ mostram que o efeito autocatalítico é observado nas estruturas densas quando comparadas às porosas, entretanto, o tamanho do poro não mostrou ter influência na morfologia das amostras durante o período de degradação, nem em função da adesão celular ${ }^{[39]}$.

Comumente, os fatores que influenciam a degradação são estudados conjuntamente. Lu et al. ${ }^{[40]}$ avaliaram a composição química e a morfologia durante a degradação in vitro e in vivo de copolímeros de PLGA. Foram preparadas estruturas porosas de PLGA (85/15) e PLGA(50/50) através do processo de adição de sal e subseqüente evaporação do solvente. Os autores concluem que a variação da concentração e tamanho dos poros também não tem influência na degradação dos materiais e que estruturas de PLGA(50/50) degradam mais rapidamente que as estruturas de $\operatorname{PLGA}(85 / 15)$, devido à maior porcentagem de unidades de ácido glicólico.

\section{Técnicas de preparo dos suportes porosos}

Como morfologia preferencial para a engenharia de tecidos, suportes porosos têm sido preparados por diversas técnicas. Publicadas na literatura científica (concomitantemente às requisições de patentes nos EUA), as técnicas de preparo de suportes porosos foram descritas em culturas de células específicas, e ainda representam um importante enfoque de desenvolvimentos ${ }^{[41]}$. Entre as técnicas podemos destacar: fiber bonding ${ }^{[42]}$, evaporação de solvente com adição e lixiviação de sal (solvent casting - particulate leaching) ${ }^{[43]}$, inversão de fases ${ }^{[44]}$, injeção de gás ${ }^{[45]}$, fused deposition modeling $(F D M)^{[46]}$, freeze-dried ${ }^{[47]} \mathrm{e}$ outras.

$\mathrm{O}$ processo de evaporação de solvente com adição e lixiviação de sal mostra-se útil na confecção de suportes com aproximadamente $70-90 \%$ de porosidade e com diâmetro de poros variando entre $50-500 \mu \mathrm{m}$. A porosidade pode ser controlada pela quantidade de sal adicionado e o tamanho dos poros pelo tamanho dos cristais de sal. A técnica permite uma boa reprodutibilidade, com interconexão dos poros ${ }^{[48]}$.

Para Mikos et al. ${ }^{[49]}$ existem desvantagens nos processos de preparação de amostras porosas que requerem o uso de solventes orgânicos. As técnicas de casting e inversão de fase podem deixar resíduos que influenciarão na cultura celular, além de impossibilitarem a inclusão de agentes farmacologicamente ativos durante o preparo. Dessa forma, métodos de extrusão de pinos e tubos com sal tem sido propostos nos últimos anos como uma alternativa ${ }^{[50,51]}$.

Na fabricação de fibras ou tubos por extrusão, altas temperaturas são requeridas e podem degradar o material gerando produtos e subprodutos tóxicos. A alta temperatura também é um fator desvantajoso quando o material está incorporado de outros materiais orgânicos, como os fatores de crescimento ${ }^{[52]}$.

Nos últimos anos, Dietmar W. Hutmacher, da Universidade Singapura, tem-se destacado mundialmente pelo preparo de fibras preparadas por fusão de PCL, através da técnica de Fused Deposition Modeling (FDM) gerando suportes porosos na forma de redes com arquitetura precisa em escala nanométrica ${ }^{[13,46]}$.

Desenvolver novas técnicas, e aprimorar as já desenvolvidas, continua sendo importante enfoque de estudo na utilização de polímeros bioreabsorvíveis na engenharia de tecidos ${ }^{[53]}$. Por exemplo, aliar o processamento do material à inclusão de fatores de crescimento tem se tornado um dos desafios atuais. Os fatores de crescimento são requeridos para promover a vascularização, vasodilatação, inibição de plaquetas, fornecimento de oxigênio e nutrientes necessários para viabilizar o sucesso da cultura de células e dos implantes ${ }^{[54]}$.

\section{Aplicações e produtos da engenharia de tecidos}

Existem diversos relatos na literatura de experimentos que visam a reprodução total ou parcial de estruturas anatômicas humanas, seja para terapia ou para reconstrução. Em franca expansão, os produtos preparados pela engenharia de tecidos (TEPs - Tissue-Engineered Products) estão em fase de aprovação pelo FDA. A Tabela 2 mostra a relação de produtos aprovados pelo FDA em comercialização ${ }^{[8]}$.

A reconstituição da pele pela engenharia de tecidos destacase como os primeiros produtos comerciais disponíveis e aprovados pelo FDA. O primeiro lançamento (Apligraf ${ }^{\circledR}$ ), indicado para úlceras em pacientes diabéticos é produzido a partir de cultura humana de prepúcio de recém-nascidos. O produto é um composto bilaminar, constituído de derme e epiderme e

Tabela 2. Produtos preparados pela engenharia de tecidos e aprovados pelo FDA (ano 2003).

\begin{tabular}{cccc}
\hline Produto & Empresa & Lançamento & Descrição \\
\hline Apligraf $^{\circledR}$ & $\begin{array}{c}\text { Organogenesis } \\
\text { Inc. }\end{array}$ & 1998 & $\begin{array}{c}\text { Equivalente de } \\
\text { Pele Humana }\end{array}$ \\
Carticel $^{\circledR}$ & Genzyme Co. & 1999 & $\begin{array}{c}\text { Cultura autóloga } \\
\text { de condrócitos }\end{array}$ \\
Dermograft $^{\mathbb{R}^{*}}$ & $\begin{array}{c}\text { Smith\&Nephew } \\
\text { Co. }\end{array}$ & 2001 & $\begin{array}{c}\text { Equivalente de } \\
\text { Pele Humana }\end{array}$ \\
OrCel $^{\circledR}$ & Ortec International & 2001 & $\begin{array}{c}\text { Equivalente de } \\
\text { Pele Humana }\end{array}$ \\
\hline
\end{tabular}

*O produto teve sua produção interrompida pela Smith\&Nephew Co. 
comercializado como um equivalente de pele humana. A camada dérmica é produzida usando-se uma cultura de fibroblastos em uma base de colágeno bovino do tipo I. Após a maturação em um bioreator, a epiderme é formada pela inoculação de queratinócitos, sobre a camada de matriz extracelular produzida pelos fibroblastos dérmicos. A ausência de outras células da epiderme no produto final, como os melanócitos, células de Langerhans (células apresentadoras de antígeno), e células de Merkel (tidas como mecanoreceptores) não limitam sua aplicação. Um produto similar ao Apligraf $^{\circledR}$, e também aprovado pelo FDA, é o $\mathrm{OrCel}^{\circledR}$, diferenciando-se por utilizar culturas de células autólogas ${ }^{[5]}$.

Outro produto também aprovado pelo FDA, mas com sua produção e comercialização descontinuada, é o Dermagraft ${ }^{\circledR}$. Produzido por técnicas da estratégia II da engenharia de tecidos, o produto é um substituto dérmico e utiliza um suporte de PLGA para o cultivo de fibroblastos humanos, também obtidos de prepúcio de recém-nascidos. O material degrada durante a cultura de células, servindo como suporte para a proliferação e secreção da matriz extracelular. Outros produtos são atualmente pesquisados para aplicações específicas na reconstrução de pele, incluindo o cultivo de fibroblastos e queratinócitos em microesferas de PLGA e outros materiais ${ }^{[56]}$.

Durante a década de 90 , grandes investimentos foram feitos em pesquisa e desenvolvimento de TEPs cartilaginosos. Atualmente, o único produto comercial aprovado pelo FDA é o Carticel $^{\circledR}$, uma expansão in vitro de cultura autóloga de condrócitos. O produto tem tido sido indicado para defeitos cartilaginosos sintomáticos dos côndilos femorais (lateral e medial) geralmente causados por traumas de repetição ${ }^{[57]}$.

Em pesquisas com tecidos cartilaginosos os polímeros bioreabsorvíveis são amplamente utilizados ${ }^{[58]}$. Liderados mundialmente pelo grupo de pesquisa do cirurgião Joseph P. Vacanti, o anestesiologista Charles Vacanti, ambos da Universidade de Harvard, e pelo engenheiro químico Robert Langer do MIT (Massachusetts Institute of Technology), a literatura tem descrito vários estudos de reconstrução de complexas estruturas anatômicas. Usando suportes de PGA e PLA é relatado reconstruções cartilaginosas na forma de uma orelha humana ${ }^{[58,59]}$, do septo nasal ${ }^{[60]}$ e traquéia ${ }^{[61]}$. Preparados pelo processo de fiber bonding o suporte é inoculado com condrócitos e inserido em bioreatores. Os resultados histológicos mostram neotecido cartilaginoso, abundante em componentes da matriz extracelular de cartilagem hialina e elástica: ácido hialurônico, sulfato de condroitina e colágeno do tipo II.

Em pesquisas aplicadas ao pâncreas, a equipe multidisciplinar do Núcleo de Terapia Celular e Molecular (NUCEL) do Instituto de Química da Universidade de São Paulo, tem destaque no transplante de ilhotas de Langerhans em pacientes diabéticos do tipo I, usando-se cápsulas de 400-600 $\mu \mathrm{m}$ diâmetro de Bioditrin (polissacarídeo conjugado de alginato com sulfato de condroitina) com poli(L-lisina) ${ }^{[62]}$.

Nos últimos anos, mundialmente são descritos experimentos que visam a reprodução total ou parcial de estruturas anatômica humana, como por exemplo: tecido hepático ${ }^{[63]}$, dente $^{[64]}$, mandíbula ${ }^{[65]}$, nervos periféricos ${ }^{[66]}$, válvulas e ductos urológicos ${ }^{[67]}$, menisco ${ }^{[68]}$, vasos ${ }^{[69]}$ e regeneração de tecido ósseo ${ }^{[70]}$.

\section{Novas Perspectivas}

O desenvolvimento de novos materiais pode ser citado como um setor de vanguarda na engenharia de tecidos. A síntese polímeros híbridos pela a adição de unidades de aminoácidos e/ou peptídeos, buscam materiais específicos e que estimulem a ancoragem celular, bem como a proliferação e diferenciação baseados nas características bioquímicas das células das membranas das células ${ }^{[71]}$. Estudos com blendas e copolímeros de materiais aprovados pelo FDA e em uso comercial também representam uma alternativa de novos suportes ${ }^{[72]}$.

Mesmo sendo estudados há décadas, os polímeros bioreabsorvíveis tem tido aplicações em segmentos pouco correlacionados. Recentemente, uma forma injetável de PLLA foi aprovada pelo FDA para comercialização indicadas à pacientes com lipodistrofia causada pelas drogas antiretrovirais na terapia contra o vírus HIV ${ }^{[73]}$.

Em cultura de células, além do uso de culturas primárias e linhagens já estabelecidas ${ }^{[74]}$, células tronco tem tido um importante destaque ${ }^{[75]}$. Avanços significativos tem sido feitos em regeneração óssea pelo uso de células mesenquimais ${ }^{[76]}$. O estudo da diferenciação celular induzida pela composição do suporte, pela morfologia e pela presença de fatores de crescimento é fundamental no contexto da regeneração de órgãos e tecidos.

\section{Conclusões}

Apesar de revolucionária e com grandes perspectivas de comercialização de novos produtos, a engenharia de tecidos tem suas limitações. $\mathrm{O}$ avanço das técnicas de cultura de células e dos suportes utilizados ainda não permite que os tecidos e órgãos sejam reproduzidos com toda sua complexidade. Tecidos feitos de um único tipo histológico vem sendo abordados conforme o exposto anteriormente. Entretanto, a reconstrução in vitro de um órgão completo é muito mais complexa, visto que eles são formados por mais de um tipo de tecido que interagem entre si e possuem funções complementares.

Baseada em conhecimentos multidisciplinares, o sucesso na reconstrução de órgãos e tecidos depende da combinação de técnicas da ciência e engenharia dos materiais, medicina e biologia celular e molecular. Assim, a formação de centros e grupos multidisciplinares demonstra ser uma necessidade para a ampliação de pesquisas relacionadas à área.

Como base para a composição de um novo tecido, os polímeros bioreabsorvíveis vêm sendo amplamente estudados para uma melhor compreensão dos fatores que influenciam sua biodegradação, bioreabsorção e a forma com que interagem com os elementos biológicos. Os produtos e técnicas já desenvolvidas servirão como um dos alicerces desta 
complexa área de conhecimento, de modo que o tecido formado seja o desejado, que a função original seja restabelecida e que o procedimento seja reprodutível e de baixo custo.

\section{Referências Bibliográficas}

1. Shin, H.; Jo, S. \& Mikos, A. G. - Biomaterials, 24, p.4353 (2003).

2. Griffith, L. G. - Acta Mater., 48, p.263 (2000).

3. Kulkarni, R. K.; Pani, K. C.; Leuman, C. \& Leonard, F. Arch. Surg. 93, p.839 (1966).

4. Liu, T. V. \& Bhatia S. N. - Adv. Drug Deliver. Rev., 56, p.1635 (2004).

5. Valimaa T. \& Laaksovirta S. - Biomaterials, 25, p.1225 (2004).

6. Ambrose C. G. \& Clanton, T. O. - Ann. Biomed. Eng., 32, p.171 (2004).

7. Langer, R. \& Tirrell, D. A. - Nature, 428, p.487 (2004).

8. Lysaght, M. J. \& Hazlehurst, A. L. - Tissue Eng., 10, p.309 (2004).

9. Griffith, L. G. \& Naughton, G. - Science, 295, p.1009 (2002).

10. Langer, R. \& Vacanti, J. P. - Science, 260, p.920 (1993).

11. Freed, L. E.; Marquis, J. C.; Nohria, A.; Emmanual, J.; Mikos, A. G. \& Langer, R. - J. Biomed. Mater. Res., 27, p.11 (1993).

12. Lloyd-Evans, M. - Mater. Today, May, p.48 (2004).

13. Hutmacher, D. W. - Biomaterials, 21, p.2529 (2000).

14. Kellomaki, M. \& Tormala, P. - Method. Mol. Biol., 238, p.1 (2004).

15. Vert, M.; Li, M. S.; Spenlehauer, G. \& Guerin, P. - J. Mater. Sci., 3, p.432 (1992).

16. Middleton, J. C. \& Tipton, A. J. - Biomaterials, 21, p.2335 (2000).

17. Elke, M.; Rolf-Joachim, M. \& Wolf-Dieter, D. - Polym. Degrad. Stabil., 80, p.485 (2003).

18. Huang, M. H.; Li, S.; Hutmacher, D. W.; Schantz, J. T.; Vacanti, C. A.; Braud, C. \& Vert, M. - J. Biomed. Mater. Res., 69A, p.417 (2004).

19. Li, S. - J. Biomed. Mater. Res., 48, p.342 (1999).

20. Li, S.; Garreu, H. \& Vert, M. - J. Mater. Sci. Mater. Med., 1, p.198 (1990).

21. Li, S.; Garreu, H. \& Vert, M. - J. Mater. Sci. Mater. Med., 1, p.342 (1990).

22. Li, S.; Garreu, H. \& Vert, M. - J. Mater. Sci. Mater. Med.., 1, p.123 (1990).
23. Ali, S. A. M.; Zhong, S.-P, Doherty, P. J. \& Williams, D. F. - Biomaterials, 14, p.648 (1993).

24. Chu, C. C. - "Biodegradable Polymeric Biomaterials: an Update Overview", in: The Biomedical Engineering Handbook, cap. 41, Bronzino, J. D. (ed.), CRC Press, (1999).

25. Sung, H. J.; Meredith, C.; Johnson, C. \& Galis, Z. S. Biomaterials, 25, p.5735 (2004).

26. Luciano, R. M.; Zavaglia, C. A. C.; Duek, E. A. R. \& Alberto-Rincon, M. C. - J. Mater. Sci. Mater. Med., 14, p.87 (2003).

27. Luciano, R. M.; Zavaglia, C. A. C. \& Duek, E. A. R. - J. Mater. Sci. Mater. Med., 14, p.87 (2003).

28. Laine, P.; Kontio, R.; Lindqvist, C. \& Suuronen, R. - Int. J. Oral Maxillofac. Surg., 33, p.240 (2004).

29. Hollinger, J. O. \& Battistone, G. C. - Clin. Orthop. Relat. Res., 207, p.290 (1986).

30. Bendix, D. - Polym. Degrad. Stabil., 59, p.129 (1998).

31. Miller, R. A.; Brady, J. M. \& Cutright, D. E. - J. Biomed. Mater. Res., 11, p.711 (1977).

32. Fisher, E. W.; Sterzel, H. J. \& Wegner, G. - Kolloid-Zuz Polym., p.251 (1973) .

33. Duek, E. A. R.; Zavaglia, C. A. C. \& Belangero, W. D. Polymer, 40, p.6465 (1999).

34. Wu, L. \& Ding, J. - Biomaterials, 25, p.5821 (2004).

35. Mikos, A. G.; Sarakinos, G.; Lyman, M. D.; Ingber, D. E.; Vacanti, J. P. \& Langer, R. - Biotech. Bioeng., 42, p.716 (1993).

36. Lu, L.; Peter, S. J.; Lyman, M. D.; Lai, H.; Leite, S. M.; Tamada, J. A.; Vacanti, J. P.; Langer, R. \& Mikos, A. G. - Biomaterials, 21, p.1595 (2000).

37. Barbanti, S. H.; Zavaglia, C. A. C. \& Duek, E. A. R. Act. Microsc., 11, p.85 (2002).

38. Barbanti, S. H.; Santos Jr. A. R.; Zavaglia, C. A. C. \& Duek, E. A. R. - J. Mater. Sci. Mater. Med., 15, p.1315, (2004).

39. Santos Jr, A. R.; Barbanti, S. H.; Duek, E. A. R.; Dolder, H.; Wada, R. S. \& Wada, M. L. F. - Artif. Org., 25, p.7 (2001).

40. Lu, L.; Peter, S. J.; Lyman, M. D.; Lai, H.; Leite, S. M.; Tamada, J. A.; Vacanti, J. P.; Langer, R. \& Mikos, A. G. - Biomaterials, 21, p.1837 (2000).

41. Williamson, M. R. \& Coombes, A. G. A. - Biomaterials, 25 , p.459 (2004).

42. Mikos, A. G.; Bao, Y.; Cima, L. G.; Ingber, D. E.; Vacanti, J. P. \& Langer, R. - J. Biomed. Mater. Res., 27, p.183 (1993). 
43. Mikos, A. G.; Sarakinos, G.; Leite, S. M.; Vacanti, J. P. \& Langer, R. - Biomaterials, 14, p.323 (1993).

44. Duek, E. A. R. \& Pezzin, A. P. T. - Polym. Degrad. Stabil., 78, p.405 (2002).

45. Harris, L. D.; Kim, B. \& Mooney, D. J. - J. Biomed. Mater. Res., 42, p.396 (1998).

46. Hutmacher, D. W.; Sittinger, M. \& Risbud, M. V. - Trends Biotechnol., 22, p.354 (2004).

47. Patist, C. M.; Mulder, M. B.; Gautier, S. E.; Maquet, V.; Jerome, R. \& Oudega, M. - Biomaterials, 25, p.1569 (2004).

48. McGlohorn, J. B.; Holder, W. D. Jr.; Grimes, L. W.; Thomas, C. B. \& Burg, K. J. - Tissue Eng., 10, p.505 (2004).

49. Mikos, A. G. \& Temenoff, J. S. - J. Biotechnol., 3, p.114 (2000).

50. Jeong, S. I.; Kim, S. H.; Kim, Y. H.; Jung, Y.; Kwon, J. H.; Kim, B. S. \& Lee Y. M. - J. Biomater. Sci. Polym. Ed., 15, p.645 (2004).

51. Barbanti, S. H.; França, M. T.; Zavaglia, C. A. C. \& Duek, E. A. R. - "Suportes de polímeros bioreabsorvíveis preparados pela técnica de fusão e lixiviação de sal", in: Anais do III Congresso Latino Americano de Órgãos Artificiais e Biomateriais (COLAOB), CD-ROM, Campinas - SP, jul (2004).

52. Chen, V. J. \& Ma, P. X. - Biomaterials, 25, p.2065 (2004).

53. Altpeter, H.; Bevis, M.J.; Grijpma, D. W. \& Feijen, J. - J. Mater. Sci. Mater. Med., 15, p.175 (2004).

54. Huang, W.; Carlsen, B.; Wulur, I.; Rudkin, G.; Ishida, K.; Wu, B.; Yamaguchi, D. T. \& Miller, T. A. - Exp. Cell Res., 299, p.325 (2004).

55. Auger, F. A.; Berthod, F.; Moulin, V.; Pouliot, R. \& Germain, L. - Biotechnol. Appl. Biochem., 39, p.263 (2004).

56. Seal, B. L.; Otero, T. C. \& Panitch, A. - Mat. Sci. Eng. Repor., 34, p.147 (2001).

57. Browne, J. E. \& Branch, T. P. - J. Am. Acad. Orthop. Surg., 8, p.180 (2000).

58. Kamil, S. H.; Vacanti, M. P.; Aminuddin, B. S.; Jackson, M. J.; Vacanti, C. A. \& Eavey, R. D. - Laryngoscope, 114, p.867 (2004).

59. Shieh, S. J.; Terada, S. \& Vacanti, J. P. - Biomaterials, 25, p.1545 (2004).
60. Tay, A. G.; Farhadi, J.; Suetterlin, R.; Pierer, G.; Heberer, M. \& Martin, I. - Tissue Eng., 10, p.762 (2004).

61. Kojima, K. \& Vacanti, C. A. - Biotechnol. Appl. Biochem., 39, p.257 (2004).

62. Maria-Engler, S. S.; Mares-Guia, M.; Correa, M. L. C.; Oliveira, E. M. C.; Aita, C. A. M.; Krogh, K.; Genzini, T.; Miranda, M. P.; Ribeiro, M.; Vilela, L.; Noronha, I. L.; Eliaschewitz, F. G. \& Sogayar, M. C. - Braz. J. Med. Biol. Res. , 34, p.691 (2001).

63. Kulig, K. M. \& Vacanti, J. P. - Transpl. Immunol., 12, p.303 (2004).

64. Duailibi, M. T.; Duailibi, S. E.; Young, C. S.; Bartlett, J. D.; Vacanti, J. P. \& Yelick, P. C. - J. Dent. Res., 83, p.523 (2004).

65. Abukawa, H.; Shin, M.; Williams, W. B.; Vacanti, J. P.; Kaban, L. B. \& Troulis, M. J. J. Oral Maxillofac. Surg., 62, p.601 (2004).

66. Komiyama, T.; Nakao, Y.; Toyama, Y.; Vacanti, C. A.; Vacanti, M. P. \& Ignotz, R. A. - J. Neurosci. Methods., 134, p.133 (2004).

67. Atala A. - Am. J. Transplant., 4, p.58 (2004).

68. Pezzin, A. P. T.; Zavaglia, C. A. C. \& Duek, E. A. R. Artif. Org., 27, p.416 (2003).

69. Opitz, F.; Schenke-Layland, K.; Cohnert, T. U.; Starcher. B.; Halbhuber. K. J.; Martin, D. P. \& Stock, U. A. Cardiovasc. Res., 63, p.719 (2004).

70. Ishaug, S. L.; Crane, G. M.; Yaszemski, M. J. \& Mikos, A. G. - Biomaterials, 19, p.1405 (1998).

71. Chen, G.; Zhou, P.; Mei, N.; Chen, X.; Shao, Z.; Pan, L. \& Wu, C. - J. Mater. Sci. Mater. Med., 15, p.671 (2004).

72. Pezzin, A. P. T.; Alberta van Ekenstein, G. O. R.; Zavaglia, C. A. C.; Brinke, G. T. \& Duek, E. A. R. - J. Appl. Polym. Sci., 88, p.2744 (2003).

73. Moyle, G. J.; Lysakova, L.; Brown, S.; Sibtain, N.; Healy, J.; Priest, C.; Mandalia, S. \& Barton, S. E. - HIV Med., 5, p.82 (2004).

74. Santos, A. R. Jr.; Ferreira, B. M.; Duek. E. A.; Dolder, H.; Wada, R. S. \& Wada, M. L. - Artif. Org., 28, p.381 (2004).

76. Yamato, M. \& Okano, T. - Mater. Today, May, p.42 (2004).

Enviado: 13/01/04

Reenviado: 20/10/04

Aprovado: 26/10/04 